Original Article

\title{
The Relationship between Rehabilitation and Changes in Depression in Stroke Patients
}

\author{
YeOn-Jae JeOng, PT $^{1)}$, Won-Cheol Kim, OT ${ }^{1)}$, Yoon-Shin Kim, MPH, PhD ${ }^{2)}$, \\ Kwan-Woo Choi, MPH ${ }^{3)}$, Soon-Yong Son, PhD $^{3)}$, Yeon-Gyu Jeong, PT, MPH ${ }^{4}{ }^{*}$ \\ 1) Rehabilitation Medicine, Hanyang University Medical Center, Republic of Korea \\ 2) Environmental and Industrial Medicine, Hanyang University Medical Center, Republic of Korea \\ 3) Radiology Department, Asan Medical Center, Republic of Korea \\ 4) Rehabilitation Medicine, Dongguk University Ilsan Medical Center: 27 Dongguk-ro, Ilsandong-gu, \\ Goyang-si, Gyeonggi-do 410-773, Republic of Korea
}

\begin{abstract}
Purpose] This study investigated the primary factors behind changes in depressive symptoms among stroke patients after 8 weeks of rehabilitation (physical, occupational, and cognitive therapy). [Methods] This study was conducted using a literature review, and electronic medical records from January, 2008 to December, 2009. Data were collected for 120 subjects with chronic stroke. [Results] Cardiac disorder, left-brain lesion, early-stage depression, activities of daily living, and cognitive function were significant predictors of the changes in depression in chronic stroke patients. [Conclusion] Post-stroke depression can be controlled by rehabilitation. Also, clinicians should comprehend and share the psychological and physical affliction, develop back-up programs, and make them comprehensively available to support the psychological and physical health of subjects with chronic stroke.

Key words: Stroke, Rehabilitation, Depression
\end{abstract}

(This article was submitted Jan. 30, 2014, and was accepted Feb. 18, 2014)

\section{INTRODUCTION}

Physical disability occurring due to stroke has a high cost, both socially and domestically. Most of the time, stroke occurs during senior years eliciting a big change in victims' social activity and independence, leading to a decrease in their physical ability ${ }^{1}$. If subjects with stroke do not receive proper protection and support physically, psychologically, and socially, they may develop mental regression, depression, discouragement, or anxiety ${ }^{2}$. These mental disorders of chronic stroke continue for a long period and affect stroke patients' quality of life ${ }^{3)}$. Nevertheless, stroke patients' social and psychological issues are typically underestimated by the medical professionals. Therefore, psychological treatment needs to be conducted together with physical treatment in order to improve patients' quality of life. Interest in post-stroke depression in Korea began 20 years ago, and various results on the relationship between the time stroke occurs and its effects on post-stroke depression have been reported ${ }^{4,5)}$. However, research into the changes in depression still lacks quality and quantity. Clinicians who treat stroke acknowledge the existence of post-stroke depression, but they are most likely to treat it

*Corresponding author. Yeon-Gyu Jeong (E-mail: assa-yk@ hanmail.net)

(C2014 The Society of Physical Therapy Science. Published by IPEC Inc. This is an open-access article distributed under the terms of the Creative Commons Attribution Non-Commercial No Derivatives (by-ncnd) License $<$ http://creativecommons.org/licenses/by-nc-nd/3.0/> . as a simple physical/psychological symptom which can be taken care of with little effort or even be ignored. Accordingly, this present study examined the extent and necessity of rehabilitation treatments on change in depression for the reduction of psychological stress in chronic stroke patients in order to propose a basis for the establishment of effective rehabilitation planning.

\section{SUBJECTS AND METHODS}

This study used the data of 120 subjects, diagnosed with stroke, who were undergoing rehabilitation therapy (30 minutes, 5 times a week, for 8 weeks) at a university hospital rehabilitation center located in Gyeonggi-do province, from January 2008 to December 2009. Subjects who had a history of mental disorders such as dementia, depression, and anxiety disorders, or were taking anti-depression medications, or had difficulties in communication were excluded from the study. The present study was supported by the Catholic University and approved by the Catholic University Institutional Review Board (Approval \# CUMC10U026). All data were collected anonymously from electronic medical records.

We collected subjects' general characteristics such as sex, age, marital status, caregiver, type of insurance, and decision-maker; health-related characteristics such as smoking, alcohol consumption, diabetes, hypertension, cardiac disorder, hyperlipidemia, and history of pre-stroke; and disease-related characteristics such as lesion region, lesion type, duration of the onset of stroke, and whether the patient currently had depression. The clinical findings of 
each subject were measured before and after rehabilitation treatment for physical, functional, and cognitive function.

The Beck Depression Inventory (BDI) was developed by $\mathrm{Beck}^{6}$. It is a survey method which is commonly used to evaluate depression. It has 21 questions, each of which are answered on a 4 point Likert scale. In this study, it was used to assess the depression levels of subjects with chronic stroke. It has a cutoff score of 21 which has high validity and reliability, ${ }^{7)}$ higher scores signifying intensifying symptoms of depression.

For cognitive impairment assessment, we used the MiniMental State Examination (MMSE), which is also used to assess the cognitive impairment of patients with serious dementia ${ }^{8)}$. In this study, we the used Mini-Mental State Examination-Korean (MMSE-K) to correspond to Korean reality, a tool consisting of 30 questions ${ }^{9)}$. The intrarater reliability has an intraclass correlation coefficient (ICC) of $0.99^{10)}$.

The Modified Barthel Index (MBI) was developed by Shah $^{11)}$. It has been shown to be a sensitive rating scale ${ }^{8)}$. In this study it was used to assess subjects' performance of activities of daily living of the subjects with chronic stroke. We used the Korean Modified Barthel Index" (K-MBI) to correspond to Korean reality, a tool consisting of 10 questions. The intrarater and interrater of reliabilities have ICCs of are 0.89 , and $0.95^{12)}$, respectively.

All the results were divided into 2 categories of subjects, those showing $>25 \%$ improvement, and those with less improvement after 8 weeks of rehabilitation.

The characteristics of the subjects are presented as frequencies and percentages. Analysis of variance (ANOVA) was conducted in order to examine the relevance between the changes in depression symptoms and the characteristics of the chronic stroke patients. Hierarchial multiple regression analysis was employed to uncover significant variations $(p<0.05)$ in univariate analysis with respect to factors influencing the changes in post-stroke depression, and forced entry was utilized to identify predictive factors. The general and health-related characteristics of stroke were entered in the first step and the disease-related characteristics of the subjects in the next. Then each of the factors of whether subjects with chronic stroke had depression early, low or high improvement of ADL, and cognitive functions after 8 weeks of rehabilitation, were entered into the prediction model. Statistical analysis was performed using SPSS ver. 17.0.

\section{RESULTS}

As shown in Table 1, after 8 weeks of rehabilitation, change in depression showed significantly positive associations with having had depression symptoms, while the relationship with lesion in the left brain was negative. Also, change in depression was significantly positively associated with improved ADL and cognitive functions. The results of hierarchial multiple regression analyses are presented in $\mathrm{Ta}-$ ble 2 . The result of analyzing factors influencing the change in depression symptoms of chronic stroke by rehabilitation, and modifying factors in the final step, the overall model showed cardiac disorder, depression, and high improve-
Table 1. The factors associated with the change in depression of stroke patients

\begin{tabular}{|c|c|c|}
\hline Variables & Characteristics & $\begin{array}{c}\text { The change in } \\
\text { depression } \\
\text { Mean (SD) }\end{array}$ \\
\hline \multirow{2}{*}{ Smoking } & Yes & $-1.07(7.06)$ \\
\hline & No & $-2.04(7.73)$ \\
\hline \multirow{2}{*}{ Alcohol intake } & Yes & $1.20(7.71)$ \\
\hline & No & $-2.00(7.74)$ \\
\hline \multirow{2}{*}{ Hypertension } & Yes & $-1.78(7.74)$ \\
\hline & No & $-1.45(6.96)$ \\
\hline \multirow{2}{*}{$\begin{array}{l}\text { Diabetes } \\
\text { mellitus }\end{array}$} & Yes & $-1.63(8.93)$ \\
\hline & No & $-1.68(6.73)$ \\
\hline \multirow{2}{*}{ Hyperlipemia } & Yes & $-0.89(7.08)$ \\
\hline & No & $-1.89(7.59)$ \\
\hline \multirow{2}{*}{ Heart disease } & Yes & $-5.58(6.69)$ \\
\hline & No & $-1.23(7.44)$ \\
\hline \multirow{2}{*}{$\begin{array}{l}\text { Pre-stroke } \\
\text { history }\end{array}$} & Yes & $-3.00(5.55)$ \\
\hline & No & $-1.45(7.73)$ \\
\hline \multirow{4}{*}{$\begin{array}{l}\text { Duration after } \\
\text { onset of stroke } \\
\text { (month) }\end{array}$} & $<3$ & $-2.49(7.71)$ \\
\hline & $3 \sim<6$ & $1.00(6.47)$ \\
\hline & $6 \sim<12$ & $1.69(7.84)$ \\
\hline & $\geq 12$ & $-3.38(5.32)$ \\
\hline \multirow{3}{*}{ Lesion type } & Infarction & $-2.08(7.53)$ \\
\hline & Hemorrhage & $-1.18(7.55)$ \\
\hline & Both & $-3.00(1.41)$ \\
\hline \multirow{4}{*}{ Lesion region* } & Left hemisphere & $1.11(6.64)$ \\
\hline & Right hemisphere & $-3.30(7.65)$ \\
\hline & Both & $-1.29(6.52)$ \\
\hline & Etc. (brainstem \& other) & $-3.67(11.5)$ \\
\hline \multirow{2}{*}{$\begin{array}{l}\text { Depression** } \\
\text { (before therapy) }\end{array}$} & Yes $(>21)$ & $-7.48(7.03)$ \\
\hline & No $(\leq 21)$ & $-7.48(7.03)$ \\
\hline \multirow{2}{*}{$\begin{array}{l}\text { Activities of } \\
\text { daily living* }\end{array}$} & High & $-3.40(7.88)$ \\
\hline & Low & $-0.51(6.99)$ \\
\hline \multirow{2}{*}{$\begin{array}{l}\text { Cognitive } \\
\text { function* }\end{array}$} & High & $-6.21(6.44)$ \\
\hline & Low & $-1.07(7.41)$ \\
\hline
\end{tabular}

ments in ADL and cognitive functions were significant predictors of change in depression.

\section{DISCUSSION}

Previous studies of the frequency of post-stroke depression have reported small differences in the $20 \sim 60 \%$ range. In the present study, the frequency of post-stroke depression was $22.5 \%$, lower than the $30 \%$ reported by other studies ${ }^{13}$, 14), because we used a cutoff score of 21 compared to 10 used in the other studies.

Post-stroke depression occasionally occurs in the chronic stage, 2 3 years following stroke ${ }^{15}$. Post-stroke depression aggravates neurological and psychological damage, adversely affecting performances on activities of daily living. Since depression increases the risk of suicide as well as raising the death rate, depression needs to be treated with 
Table 2. Hierarchial multiple regression with the change in depression as the dependent variable

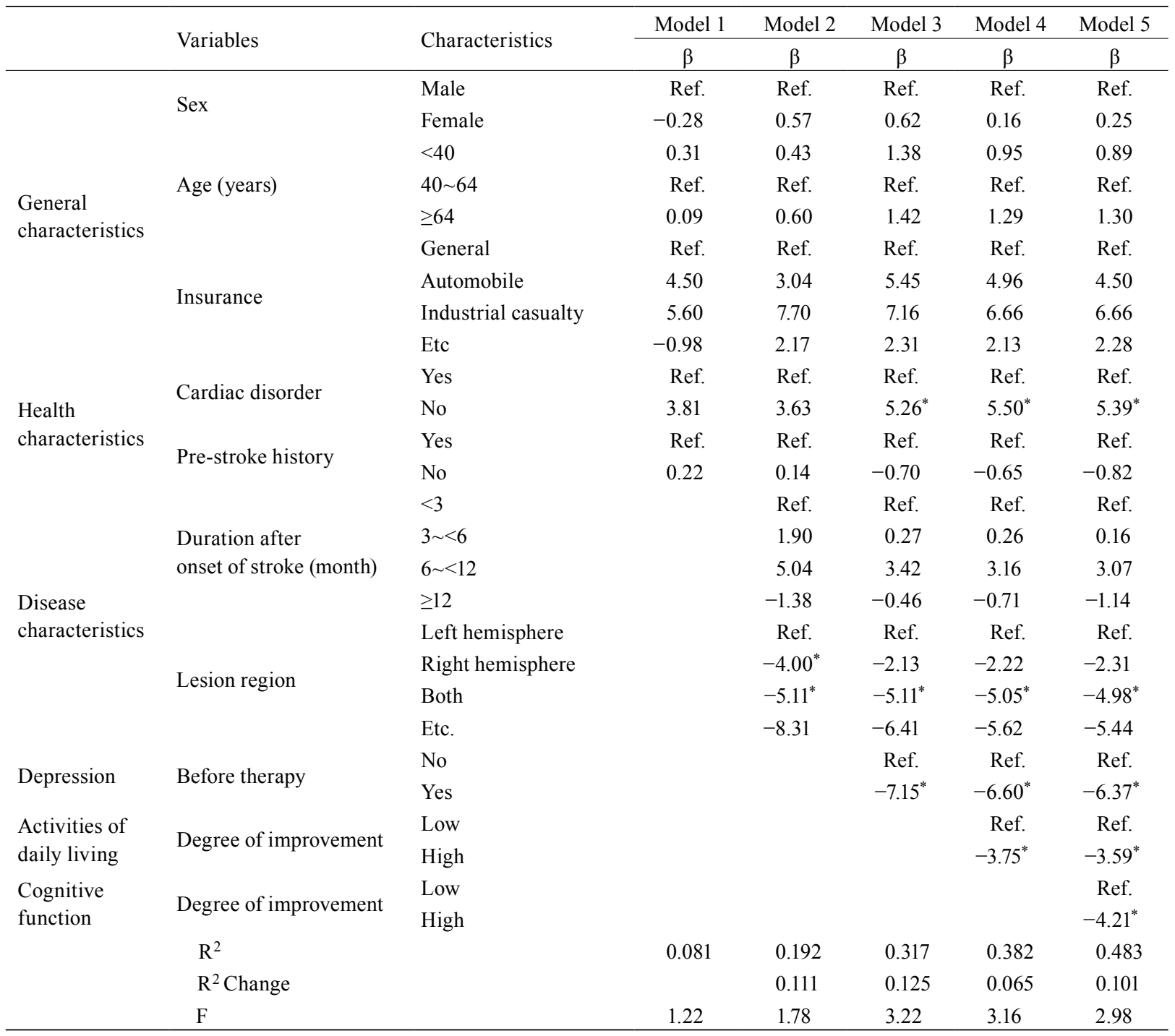

more care and interest in post-stroke rehabilitation ${ }^{16)}$. Due to this situation, this research investigated factors that elicit changes in depressive symptoms among stroke patients after 8 weeks of rehabilitation, and compared how the related factors affected change in depression. After 8 weeks of rehabilitation, history of cardiac disorder, lesion in the left brain, early-stage depression, and higher improvement in activities of daily living and cognitive function were identified as factors influencing change in depression.

The factor that had the greatest influence on the change in depression elicited by rehabilitation was early-stage depression at the beginning of the treatment (12.5\%). According to research, regular exercise or leisure activities reduced depression in elderly depressive patients, and increased their life satisfaction ${ }^{17,18)}$. However, another study didn't find any significant change in depression symptoms elicited by the physical therapy itself even though the subjects' depression scores reduced by a little ${ }^{19)}$. Our present study focused on a broad spectrum of rehabilitation, i.e., physical performance of activities of daily living, and cognitive exercises, rather than physical exercise alone as in the previous study.
The improvement of cognitive function also influenced change in depression $(10.1 \%)$. Andersen ${ }^{20)}$ stated that disorder of cognitive function was the main reason for depression among stroke patients, since the patients who showed improvements in cognitive function also showed improvements in depression. Also, stroke patients who showed improvements in cognitive function in the 3 months following the onset of stroke showed greater improvements in their levels of depression ${ }^{21)}$, a result similar to that of our present study. This implies that cognitive function has to be taken care of first in order to improve depression. However, many studies have reported that there is no correlation between depression and cognitive function ${ }^{22,23)}$.

The improvement of activities of daily living influenced change in depression (6.5\%). Robinson ${ }^{24)}$ conducted a 2 year follow-up study and reported that stroke patients who showed improvements in performance of activities of daily living showed improvements in depression, similar to the results of our present study. Other studies have reported that depression and activities of daily living show a correlation, since the stroke patients who had depression were more de- 
pendent on others and had more severe psychological disorders than those who did not have depression ${ }^{25,26)}$. However, it has also been reported that there is no major correlation between depression and activities of daily living ${ }^{27}$.

Left brain lesion and cardiac disorder also influenced change in depression (11.1\%). According to the study of Verdelho ${ }^{28)}$, similar to the results of our present study, stroke patients who had severe damage in the left brain were more likely to have severe depression than patients who had damage in the other parts of the brain, and that stroke patients who had severe damage in the left-brain, right brain basal ganglia, or frontal pole were more likely to have severe depression than other patients ${ }^{26}$. However, a few studies have also reported that lesion region and post-stroke depression are not correlatied ${ }^{29)}$. In the present study, patients with cardiac disorder had a higher probability of having severe depression than the patients who did not. This result is supported by the findings of other studies, that patients with myocardial infarction and coronary disease have higher rates of depression ${ }^{30,31)}$. Nevertheless, Leentjens ${ }^{32)}$ stated that there were no correlations between hypertension, diabetes, cardiac disorder, or smoking, etc with depression.

The limitations of this study were as follows. First, because our sampling consisted of patients limited to a single university hospital, the current findings cannot be generalized to all victims of stroke. Second, this study ruled out aphasia patients with stroke, since aphasia could have been caused by left brain lesion which could have affected our results. We need to include aphasia patients in a future study. Also, because the present study was conducted only for a short 8-week rehabilitation period, our results cannot be generalized until further studies on the long-term effects of rehabilitation on change in depression symptoms have been performed. Finally, we did not consider factors such as financial problem, social support, self-efficacy, and selfesteem. According to $\mathrm{Aben}^{33)}$, depression in stroke has a great influence on psychological and environmental factors. The results of the present study are meaningful in that cognitive and physical and functional exercises improved the subjects' depressive symptoms. In addition, our results also provide objective data for studies of the relationship between depression and rehabilitation. To clarify the effectiveness of therapies for reducing post-stroke depression, further study addressing these limitations is needed

\section{REFERENCES}

1) Yoon TS: The Influence of depressive symptoms on cognitive and functional recovery in chronic stroke patients. Dongguk University, Graduate School of Medicine, Masters Dissertation, 2009.

2) Lee IG, Han HY, Kim HS, et al.: Emotional disorder of stroke patients. J Korean Acad Rehab Med, 1995, 12: 33-38.

3) Lawrence L, Christie D: Quality of life after stroke: a three-year follow-up. Age Ageing, 1979, 8: 167-172. [Medline] [CrossRef]

4) Wilkinson PR, Wolfe CD, Warburton FG, et al.: A long-term follow-up of stroke patients. Stroke, 1997, 28: 507-512. [Medline] [CrossRef]

5) Sharpe M, Hawton K, House A, et al.: Mood disorders in long-term survivors of stroke: associations with brain lesion location and volume. Psychol Med, 1990, 20: 815-828. [Medline] [CrossRef]

6) Beck AT, Ward CH, Mendelson M, et al.: An inventory for measuring depression. Arch Gen Psychiatry, 1961, 4: 561-571. [Medline] [CrossRef]

7) Hahn HM, Yum TH, Shin YW, et al.: A standardization study of Beck depression inventory in Korea. J Korean Neuropsychiatr Assoc, 1986, 25 : 487-500.
8) Mahoney FI, Barthel DW: Functional evaluation: the barthel index. Md State Med J, 1965, 14: 61-65. [Medline]

9) Park JH, Kwon YC: Standardization of Korean version of the Mini-Menta State Examination (MMSE-K) for use in the elderly: PartII. diagnostic validity. J Korean Neuropsychiatr Assoc, 1989, 28: 508-512.

10) Park RJ, Lee HO, Kim SH: Correlation analysis between MBI and MMSE after exercise program for dementia elderly. J Kor Soc Phys Ther, 2000, 12: 83-93.

11) Shah S, Vanclay F, Cooper B: Improving the sensitivity of the Barthel Index for stroke rehabilitation. J Clin Epidemiol, 1989, 42: 703-709. [Medline] [CrossRef]

12) Son HH, Oh JL, Park RJ: The effect of an exercise program on activities of daily living (ADL), balance and cognition in elderly individuals with alzheimer's disease and vascular dementia. J Kor Soc Phys Ther, 2010, 22: 53-60.

13) Paolucci S: Epidemiology and treatment of post-stroke depression. Neuropsychiatr Dis Treat, 2008, 4: 145-154. [Medline] [CrossRef]

14) House A, Dennis M, Warlow C, et al.: Mood disorders after stroke and their relation to lesion location. A CT scan study. Brain, 1990, 113: 11131129. [Medline] [CrossRef]

15) Robinson RG, Price TR: Post-stroke depressive disorders: a follow-up study of 103 patients. Stroke, 1982, 13: 635-641. [Medline] [CrossRef]

16) Kim HG, Oh KJ: Post stroke depression a review on it's prevalence, course and relation to lesion location. Korean J Clin Psychol, 1996, 15: 217-234.

17) McAuley E, Shaffer SM, Rudolph D: Affective responses to acute exercise in elderly impaired males: the moderating effects of self-efficacy and age. Int J Aging Hum Dev, 1995, 41: 13-27. [Medline] [CrossRef]

18) Kwon WA, Kim HS: A study on the correlation between the types of leisure activity and depression in the elderly in bukgu district, daegu city. J Kor Soc Phys Ther, 2008, 20: 51-59.

19) Yi SJ, Jeong SY: Change of depression according to physical therapy in stroke patients. J Kor Soc Phys Ther, 2001, 13: 33-40.

20) Andersen G, Vestergaard K, Riis JO, et al.: Dementia of depression or depression of dementia in stroke? Acta Psychiatr Scand, 1996, 94: 272-278. [Medline] [CrossRef]

21) Murata $Y$, Kimura M, Robinson RG: Does cognitive impairment cause post-stroke depression? Am J Geriatr Psychiatry, 2000, 8: 310-317. [Medline] [CrossRef]

22) Robinson RG, Schultz SK, Castillo C, et al.: Nortriptyline versus fluoxetine in the treatment of depression and in short-term recovery after stroke: a placebo-controlled, double-blind study. Am J Psychiatry, 2000, 157: 351359. [Medline] [CrossRef]

23) Lipsey JR, Robinson RG, Pearlson GD, et al.: Nortriptyline treatment of post-stroke depression: a double-blind study. Lancet, 1984, 1: 297-300. [Medline] [CrossRef

24) Robinson RG, Starr LB, Lipsey JR, et al.: A two-year longitudinal study of post-stroke mood disorders: dynamic changes in associated variables over the first six months of follow-up. Stroke, 1984, 15: 510-517. [Medline] [CrossRef]

25) Morris PL, Raphael B, Robinson RG: Clinical depression is associated with impaired recovery from stroke. Med J Aust, 1992, 157: 239-242. [Medline]

26) Robinson RG: Poststroke depression: prevalence, diagnosis, treatment and disease progression. Biol Psychiatry, 2003, 54: 376-387. [Medline] [CrossRef]

27) van de Weg FB, Kuik DJ, Lankhorst GJ: Post-stroke depression and functional outcome: a cohort study investigating the influence of depression on functional recovery from stroke. Clin Rehabil, 1999, 13: 268-272. [Medline] [CrossRef]

28) Verdelho A, Hénon H, Lebert F, et al.: Depressive symptoms after stroke and relationship with dementia: a three-year follow-up study. Neurology, 2004, 62: 905-911. [Medline] [CrossRef]

29) Carson AJ, MacHale S, Allen K, et al.: Depression after stroke and lesion location: a systematic review. Lancet, 2000, 356: 122-126. [Medline] [CrossRef]

30) Carney RM, Rich MW, Tevelde A, et al.: Major depressive disorder in coronary artery disease. Am J Cardiol, 1987, 60: 1273-1275. [Medline] [CrossRef]

31) Thomas AJ, O’Brien JT, Barber R, et al.: A neuropathological study of periventricular white matter hyperintensities in major depression. J Affect Disord, 2003, 76: 49-54. [Medline] [CrossRef]

32) Leentjens AF, Aben I, Lodder J, et al.: General and disease-specific risk factors for depression after ischemic stroke: a two-step Cox regression analysis. Int Psychogeriatr, 2006, 18: 739-748. [Medline] [CrossRef]

33) Aben I, Denollet J, Lousberg R, et al.: Personality and vulnerability to depression in stroke patients: a 1-year prospective follow-up study. Stroke, 2002, 33: 2391-2395. [Medline] [CrossRef] 